\title{
A short communication on mapping the pattern and problems associated with internet usage among youths in Malaysia: some preliminary results
}

\begin{abstract}
This study aims to determine the pattern and problems of internet usage among youths in Malaysia educational institution. Albeit the presentation of preliminary data from actual study, it provides a 'draft map' to the pattern and problems of internet usage among youths in Malaysia. To elicit the data, questionnaires were distributed to 47 undergraduate students of Universiti Putra Malaysia. Analysis performed has confirmed that respondents used internet mainly for seeking information with regard to their studies and to communicate with friends. Financial constraint and information overloaded are among problems faced by them in using the internet.
\end{abstract}

Keyword: Youths development; Internet usage; Patterns of internet usage; Problems of internet usage 